\title{
Optimal Monetary Policy Under Sectoral Interconnections
}

\author{
Swapnil Singh ${ }^{1,2} \cdot$ Roel Beetsma $a^{3,4,5,6,7,8}$ \\ Published online: 13 July 2018 \\ (c) The Author(s) 2018
}

\begin{abstract}
We explore the role of intersectoral factor demand linkages for the design of optimal monetary policy. A two-sector new-Keynesian model is developed in which the sectors are connected through factor demand linkages. Moreover, they differ in price stickiness. We obtain two important results: first, the presence of factor demand linkages causes amplification effects in resource mis-allocation and, hence, the concern for price stability becomes relatively more important. Second, the optimal price index is not the same as the aggregate price index, although it does not directly depend on the factor demand linkages themselves. Furthermore, based on the micro-founded loss function we derive a policy rule that implements the optimal allocation.
\end{abstract}

Keywords Optimal monetary policy · Factor demand linkages · Price stickiness · Loss function · Optimal policy rule

JEL Classification E31 $\cdot$ E32 $\cdot$ E52 $\cdot$ E58

\section{Introduction}

Recent monetary policy literature has been concerned with optimal monetary policy in a multi-sector economy (Aoki 2001; Woodford 2010; Petrella and Santoro 2011). The focus of this literature is on two-sector models in which sectors differ in terms of price stickiness. The monetary authority then faces the problem of stabilizing an appropriately-defined inflation measure and an appropriately-defined output gap. This problem differs in two ways from that of optimal monetary policy in a one-sector

We thank two anonymous referees for their very useful remarks..

Electronic supplementary material The online version of this article (https://doi.org/10.1007/s10645018-9327-x) contains supplementary material, which is available to authorized users.

Roel Beetsma

R.M.W.J.Beetsma@uva.nl

Extended author information available on the last page of the article 
new-Keynesian model: the presence of price indices for individual sectors introduces a relative price component in the economy, while aggregate inflation is a weighted average of the sectoral inflation rates. These complications make the problem of optimal monetary policy non-trivial. For example, in the context of a two-sector economy with a sector with fully flexible prices and a sector with sticky prices, Aoki (2001) shows that the optimal monetary policy involves targeting the inflation rate in the sticky-price sector. The intuition for this result is that, while price fluctuations in the flexible sector lead to only transitory and non-distorting relative price fluctuations, relative price fluctuations originating in the sticky-price sector cause distortions in resource allocation and, hence, reduce welfare.

Although the result of Aoki (2001) provides an important insight, it is highly theoretical in nature. For example, the empirical results by Bils and Klenow (2004) suggest that there does not exist a single sector with fully flexible prices, although they do find that price stickiness differs across the sectors. ${ }^{1}$ In particular, they report that the sector with the lowest degree of price stickiness is the transportation sector where $40 \%$ of the prices change every month, while the most sticky sector is medical care where only $10 \%$ of the prices are revised every month. In addition, Kim and Kim (2006) and Holly and Petrella (2012) argue that inter-sectoral factor demand linkages are important for the transmission of both sectoral and aggregate shocks.

Keeping these two empirical facts in mind, this paper explores the optimal monetary policy in a multi-sector economy in which sectors differ in terms of price stickiness, while they are connected through intersectoral factor demand linkages. ${ }^{2}$ To answer this question we develop a two-sector new-Keynesian model with these two features and which we calibrate to the U.S. economy. Following Jones (2011), we introduce factor demand linkages by assuming that intermediate firms in each sector use final output as an input in producing goods. This assumption is justified by the fact that sectors generally produce both for final use and for use as intermediates in other sectors. ${ }^{3}$ We follow Woodford (2003) and derive the micro-founded loss function and the implied optimal policy rule.

An alternative way of modelling factor demand linkages would be to assume that each intermediate sector draws part of its inputs directly from the other intermediate sector. However, there is no single "correct" way of modelling factor demand linkages, because in reality producers use as inputs unfinished and finished products, such as cars. Our approach implies that each sector effectively uses as input intermediates produced by the other sector as well as by the own sector. Hence, for given factor demand linkage parameter the input fraction made up by the other sector's intermediates is smaller than under the alternative modelling approach. With an appropriate adjustment of the factor demand linkage parameter the two modelling approaches are essentially identical. The only difference is that our approach implicitly allows each intermediate producer to also draw inputs from other producers in its own sector, which

\footnotetext{
1 See Table 2 in Bils and Klenow (2004).

2 For brevity, from now on we will refer to "intersectoral factor demand linkages" as "factor demand linkages".

3 As the objective of this paper is to provide an analytical characterization of optimal monetary policy, and not quantitative results, we refrain from assuming that factor demand linkages differ between sectors.
} 
is not the case under the alternative approach, but which would be more realistic when sectors are defined at a highly aggregate level. However, we would expect our main results to be similar in qualitative terms under the two approaches.

The availability of an analytical expression for the policy rule allows us to provide a complete characterization of monetary authority's response to sectoral productivity shocks. We obtain a number of interesting results. First, factor demand linkages amplify economic fluctuations. When a sector experiences a positive productivity shock, this raises individual consumption through an increase in the real wage. The resulting increase in consumption demand leads to an increase in the demand for final output and, hence, in the demand for intermediates. In turn, this magnifies the demand for final output, as the latter serves as an input for the intermediate sectors.

Second, the optimal price index to target by the monetary authority is a weighted average of the prices of the two sectors, with the weights being a non-linear increasing function of the degrees of price stickiness of the two sectors. This corroborates the finding of Aoki (2001), but in a more general setting. Hence, with differences in sectoral price stickiness, the monetary authority will react relatively more aggressively to inflation in the more sticky price sector.

Third, although factor demand linkages do not directly affect the optimal price index, they affect the trade-off between stabilizing the output gap and the optimal price index. When factor demand linkages become stronger, implying that a larger fraction of the final product is used as an input into the production of intermediates, the coefficients of the endogenous variables in the optimal interest rate rule tend towards zero. Intuitively, stronger factor demand linkages imply that a smaller fraction of final output is consumed. In the limiting case in which all the final output is again used as intermediate, the consumption share of final output drops to zero and the monetary authority becomes no longer concerned with stabilizing the economy. However, it is important not to conclude from this result that stronger factor demand linkages reduce the welfare cost of productivity shocks, as the share of consumption in total production also becomes smaller.

Fourth, we show that for relatively weak factor demand linkages and holding constant the price stickiness in the flexible sector, the welfare cost associated with sectoral productivity shocks is non-monotonic in the degree of price stickiness of the sticky sector, reaching a maximum for some degree of price stickiness between full flexibility and complete stickiness. This result runs counter to the standard finding that welfare losses are monotonically increasing in the degree of price stickiness. The intuition for our result is as follows. In the standard model the monetary authority faces a trade-off between output and aggregate inflation stabilization. However, in the present framework, due to the presence of two sectors, the objective of monetary policy is to stabilize output and the two sectoral inflation rates. With the interest rate as the only instrument, the monetary authority primarily trades off the stabilization of output and sticky-sector inflation, leaving inflation fluctuations in the flexible sector largely unchecked. Its fluctuations are affected by the strength of the factor demand linkages in the economy.

Fifth, we also explore the costs of sub-optimal policies. The first type of suboptimality arises from the monetary authority not knowing the true value of the factor demand linkages in the economy. We find that setting monetary policy according to the optimal interest rate rule, but based on an incorrect assumption about the strength of 
the factor demand linkages, only produces a limited additional welfare cost. However, ignoring differences in sectoral price stickiness by linking the inflation weights in the welfare loss function solely to the relative sector sizes leads to substantially higher welfare losses.

Our paper is related to a number of contributions in the literature. First, while the current paper focuses on a closed economy, the modelling set-up borrows from a large monetary policy literature in an open-economy framework. Benigno (2004) finds that if the regions in a two-region currency area feature the same degree of nominal stickiness, then optimal monetary policy focuses on weighted-average inflation with relative weights based on the relative economic sizes of the regions. Lombardo (2006) shows that this result breaks down in the presence of other types of asymmetries. Beetsma and Jensen (2005) add to this literature by focusing on fiscal stabilization under commitment and discretion. As Horvath (1998, 2000) makes clear, factor demand linkages are an important feature of any economy and determine to a large extent how the sectoral and aggregate shocks propagate through the economy. Moreover, Bouakez et al. (2009) show how the co-movement between spending on durables and non-durables due to monetary policy shocks can be explained by the presence of factor demand linkages. Our paper complements this work by exploring the role of optimal monetary policy in the presence of such linkages. Barsky et al. (2016) and Petrella et al. (2017) show that the presence of durable goods in the economy can affect monetary policy. However, for two reasons we do not incorporate durable goods into our analysis. First, in practice the consumption of durable goods comes with transaction costs, e.g. see Chetty and Szeidl (2007). This implies that the consumption of durable goods during a crisis can be very different from that during a boom. As Barsky et al. (2016) do not explicitly model such transaction costs, it is not clear that durable goods consumption really matters for monetary policy. Second, durable goods consumption comprises only about $15 \%$ of total consumption.

The paper closest to our paper is Petrella and Santoro (2011). They also explore optimal monetary policy under factor demand linkages. However, apart from a number of modelling differences, our paper also differs in terms of its analysis. We explicitly derive the optimal interest rate rule that allows us to characterize analytically how the weights associated with the different endogenous variables vary with respect to the sectors' relative weights in the economy, the different degrees of price stickiness of the sectors and strength of the factor demand linkages. Furthermore, we explore welfare losses for situations in which monetary policy is sub-optimal.

The remainder of this paper is organized as follows. Section 2 presents the model, Sect. 3 derives the sticky-price equilibrium and the optimal monetary policy rule. Section 4 presents the results. Section 5 concludes the main body of the paper. Most derivations are relegated to the appendices, which are not for publication, but are available upon request or via the authors' homepages.

\section{The Model}

There are three types of agents in the economy: a representative household, firms and the public authorities, consisting of a monetary authority and a government. The 
economy is divided into two sectors that differ in their degrees of price stickiness. The more sticky sector (the "sticky sector") is referred to as sector $s$, while the less sticky sector (the "flexible sector") is referred to as sector $f$. To model the factor demand linkages in an intuitive way, we assume that intermediate firms buy output from final output producers and use this as an input into their own production. As the final output producers combine the outputs from all the intermediate producers to generate their product, this assumption connects all intermediate firms with each other and introduces the factor demand linkages. Price stickiness introduces a nominal friction, whereas monopolistic competition introduces a real rigidity. Each component of the economy is described in detail below.

\subsection{Households}

The representative household's lifetime utility is

$$
\mathbb{E}_{0} \sum_{t=0}^{\infty} \beta^{t} U\left(C_{t}, N_{t}\right)
$$

where

$$
U\left(C_{t}, N_{t}\right)=\frac{C_{t}^{1-\sigma}}{1-\sigma}-\frac{N_{t}^{1+\phi}}{1+\phi},
$$

$\beta$ is the household's time discount factor, $C_{t}$ is the consumption of final output by the household in period $t$ and $N_{t}$ is the labor supplied by the household in period $t$. The household maximizes its lifetime utility (1) over $\left\{C_{t}, N_{t}, B_{t+1}\right\}_{t=0}^{\infty}$ subject to the period $t$ inter-temporal budget constraint,

$$
P_{t} C_{t}+\mathbb{E}_{t} Q_{t, t+1} B_{t+1} \leq W_{t} N_{t}+B_{t}+\Upsilon_{t}-\mathcal{T}_{t}
$$

where $P_{t}$ is the price of one unit of consumption, $B_{t+1}$ is the portfolio of one-period state-contingent Arrow-Debreu securities, $Q_{t, t+1}$ is the price of $B_{t+1}, W_{t}$ is the nominal wage, $\Upsilon_{t}$ are firm profits and $\mathcal{T}_{t}$ are lump-sum taxes. The first-order conditions of the household's problem are given as

$$
\frac{N_{t}^{\phi}}{C_{t}^{-\sigma}}=\frac{W_{t}}{P_{t}}, \quad 1=\beta \mathbb{E}_{t}\left[\left(\frac{C_{t+1}}{C_{t}}\right)^{-\sigma} \frac{R_{t}}{\Pi_{t+1}}\right],
$$

where $R_{t}$ is the risk-free short-term nominal interest rate. The first equation regulates the intratemporal trade-off between consumption and leisure, while the second equation is the Euler equation for consumption. Following Woodford (2003), we have assumed that there are no monetary frictions making it worthwhile for households to hold liabilities of the monetary authority that earn a sub-standard rate of return. We further assume that the monetary authority can control the short-term nominal interest rate. Ruling out arbitrage we can write $R_{t}=1 / \mathbb{E}_{t} Q_{t, t+1}$. The gross inflation rate is 
given as $\Pi_{t+1}=P_{t+1} / P_{t}$. For future use, we define the nominal stochastic discount factor as

$$
Q_{t, \tau}=\beta^{\tau-t} \frac{U_{C, \tau}}{U_{C, t}} \frac{P_{t}}{P_{\tau}},
$$

where $U_{C, t}$ denotes the marginal utility of consumption in period $t$. The expression for $Q_{t, \tau}$ is the factor by which financial markets discount random nominal income in any future period $\tau$ to assess the claim to that income in period $t$.

\subsection{Firms}

There is a unit mass of monopolistically competitive intermediate goods producing firms located on the interval $[0,1]$, with the sticky sector firms located on the subinterval $[0, n)$ and flexible sector firms located on the sub-interval $[n, 1]$. Firms are indexed by the subscript $i$. Firms in both sectors can change prices under the Calvo (1983) price-setting mechanism. Hence, every period a fixed fraction of the firms in each sector gets the chance to reset their prices. The fraction of price-resetting firms in the sticky sector is lower than in the flexible sector. Besides the intermediate goods producers, there are the final goods producers. A key extension of the existing literature is that the intermediate goods producers combine labour input hired in a competitive market with final output to create their product. Because the final output producers combine all the intermediate goods to create the final product, this introduces factor demand linkages.

The final output producers are perfectly competitive and operate in two stages. ${ }^{4}$ First, using a Dixit and Stiglitz (1977) CES aggregation technology they combine the various intermediate outputs produced in a given sector into a sectoral product. Second, again using a CES aggregation technology, they combine the two sectoral products into the final product of the economy. Aggregate final output is

$$
Y_{t}=\frac{Y_{s, t}^{\eta} Y_{f, t}^{1-\eta}}{\eta^{\eta}(1-\eta)^{1-\eta}},
$$

where $Y_{s, t}$ and $Y_{f, t}$ are the sectoral aggregate outputs and the parameter $\eta$ captures the weight of sector $s$ in the final product. The price of one unit of the final product is a composite of the price indices $P_{s, t}$ and $P_{f, t}$ of the sectors $s$, respectively $f$ :

$$
P_{t}=P_{s, t}^{\eta} P_{f, t}^{1-\eta}
$$

The final output producers' problem is to minimize the cost of production. The resulting demands for input from the two sectors are

$$
Y_{s, t}=\eta T_{t}^{\eta-1} Y_{t}, \quad Y_{f, t}=(1-\eta) T_{t}^{\eta} Y_{t}
$$

\footnotetext{
4 By "perfectly competitive" we mean that the final output producers are price takers. Hence, they take the price of final output and the prices charged by the intermediate producers as given.
} 
where $T_{t}=P_{s, t} / P_{f, t}$ is the relative price index of the two sectors.

The aggregate sector-level outputs are

$$
Y_{s, t}=\left[\left(\frac{1}{n}\right)^{\frac{1}{\epsilon}} \int_{0}^{n} Y_{s, t}(i)^{\frac{\epsilon-1}{\epsilon}} d i\right]^{\frac{\epsilon}{\epsilon-1}}, \quad Y_{f, t}=\left[\left(\frac{1}{1-n}\right)^{\frac{1}{\epsilon}} \int_{n}^{1} Y_{f, t}(i)^{\frac{\epsilon-1}{\epsilon}} d i\right]^{\frac{\epsilon}{\epsilon-1}},
$$

where $\epsilon$ is the elasticity of substitution between each pair of intermediate goods, while $Y_{a, t}(i)$ is the output of intermediate producer $i$ in sector $a=\{s, f\}$. Hence, the demand for each intermediate product is

$$
Y_{s, t}(i)=\frac{1}{n}\left(\frac{P_{s, t}(i)}{P_{s, t}}\right)^{-\epsilon} Y_{s, t}, \quad Y_{f, t}(i)=\frac{1}{1-n}\left(\frac{P_{f, t}(i)}{P_{f, t}}\right)^{-\epsilon} Y_{f, t},
$$

where $Y_{a, t}(i)$ is the demand faced by intermediate producer $i$ in sector $a, P_{a, t}(i)$ is the price charged by producer $i$ in sector $a$, and $P_{a, t}$ is the sector $a$ price index. The sectoral price indices are defined as

$$
P_{s, t}=\left[\frac{1}{n} \int_{0}^{n} P_{s, t}(i)^{1-\epsilon} d i\right]^{\frac{1}{1-\epsilon}}, \quad P_{f, t}=\left[\frac{1}{1-n} \int_{n}^{1} P_{f, t}(i)^{1-\epsilon} d i\right]^{\frac{1}{1-\epsilon}} .
$$

The production technology of intermediate producer $i$ in sector $a=\{s, f\}$ is given by

$$
Y_{a, t}(i)=Z_{a, t} X_{a, t}(i)^{\chi} N_{a, t}(i)^{1-\chi},
$$

where $Z_{a, t}, a=\{s, f\}$, is a sector-specific productivity shock, $X_{a, t}(i)$ is the amount of the final output used as input by producer $i$ in sector $a$ and $N_{a, t}(i)$ is the labor input. The parameter $0<\chi<1$ is the share of final output as input in the production of $Y_{a, t}(i)$. Hence, a higher value of $\chi$ implies stronger factor demand linkages in the economy.

The intermediate goods producer faces two problems. First, given the demand for its output and taking the prices of the production factors as given, she minimizes the cost of production. This yields her inputs demands:

$$
X_{a, t}(i)=\Gamma^{1-\chi}\left(\frac{W_{t}}{P_{t}}\right)^{1-\chi} \frac{Y_{a, t}(i)}{Z_{a, t}}, \quad N_{a, t}(i)=\Gamma^{-\chi}\left(\frac{W_{t}}{P_{t}}\right)^{-\chi} \frac{Y_{a, t}(i)}{Z_{a, t}}, \quad a=\{s, f\},
$$

where $\Gamma=\frac{\chi}{1-\chi}$ is a constant. As the production technology of each intermediate producer features constant returns-to-scale, the real marginal cost within a sector will be the same for all producers and is given as

$$
M C_{a, t}=\frac{\Gamma^{1-\chi}}{\chi}\left(\frac{W_{t}}{P_{t}}\right)^{1-\chi} \frac{1}{Z_{a, t}}, \quad a=\{s, f\},
$$


Second, assuming a Calvo (1983) price-setting mechanism, whenever the intermediate good producer gets the chance to reset her price, she does this with the aim of maximizing nominal profits, while taking into account the uncertainty of again being able to revise this price in the future. Hence, she resets her price to its optimum:

$$
P_{a, t}^{o p t}=\frac{\epsilon}{(\epsilon-1)\left(1+\tau_{a}\right)} \frac{\mathbb{E}_{t} \sum_{j=t}^{\infty}\left(\theta_{a} \beta\right)^{j-t} M C_{a, j} C_{j}^{-\sigma} P_{a, j}^{\epsilon-1} P_{j} Y_{j}}{\mathbb{E}_{t} \sum_{j=t}^{\infty}\left(\theta_{a} \beta\right)^{j-t} C_{j}^{-\sigma} P_{a, j}^{\epsilon-1} Y_{j}},
$$

where $1-\theta_{a}$ is the fraction of firms in sector $a$ that get the chance to reset their price and $\tau_{a}$ is a subsidy provided by the government to intermediate producers in sector $a$. Hence, parameter $\theta_{a}$ measures the degree of price stickiness in sector $a$. Notice that the new optimal price is the same for all the producers within the same sector.

The remainder of this subsection focuses on sector $s$, while the derivations for sector $f$ yield corresponding expressions. To facilitate the solution, following Woodford (2010) we can write (11) as

$$
\mu_{s} \frac{H_{s, t}}{K_{s, t}}=T_{t}^{1-\eta}\left[\frac{1}{1-\theta_{s}}-\left(\frac{\theta_{s}}{1-\theta_{s}}\right) \Pi_{s, t}^{\epsilon-1}\right]^{\frac{1}{1-\epsilon}}
$$

where $\Pi_{s, t}$ is sector level inflation in sector $s$ and $\mu_{s}=\frac{\epsilon}{(\epsilon-1)\left(1+\tau_{s}\right)}$. It is convenient to write $H_{s, t}$ and $K_{s, t}$ in recursive form as

$$
\begin{gathered}
H_{s, t}=\frac{\Gamma^{1-\chi}}{\chi} \frac{1}{Z_{s, t}} C_{t}^{-\sigma \chi} N_{t}^{\phi(1-\chi)} T_{t}^{(1-\eta)(\epsilon-1)} Y_{t}+\theta_{s} \beta \mathbb{E}_{t}\left(\Pi_{s, t+1}^{\eta \epsilon} \Pi_{f, t+1}^{(1-\eta) \epsilon} H_{s, t+1}\right) \\
K_{s, t}=C_{t}^{-\sigma} T_{t}^{(1-\eta)(\epsilon-1)} Y_{t}+\theta_{s} \beta \mathbb{E}_{t}\left(\Pi_{s, t+1}^{\eta(\epsilon-1)} \Pi_{f, t+1}^{(1-\eta)(\epsilon-1)} K_{s, t+1}\right)
\end{gathered}
$$

Aggregating the outputs produced by sector $s$, one can write

$$
Y_{s, t} D_{s, t}=Z_{s, t} X_{s, t}^{\chi} N_{s, t}^{1-\chi}
$$

where $D_{s, t}=\frac{1}{n} \int_{0}^{n}\left(\frac{P_{s, t}(i)}{P_{s, t}}\right)^{-\epsilon} d i$ measures the price dispersion in sector $s$ arising from the price stickiness. Using Jensen's inequality one can show that $D_{s, t} \geq 1$. Hence, compared to a situation of fully flexible prices, price stickiness depresses the aggregate production in a sector, because the price dispersion produces a suboptimal composition of the individual intermediates that are aggregated into the composite sectoral product. The price dispersion $D_{s, t}$ can be written in a recursive form as

$$
D_{s, t}=\left(1-\theta_{s}\right)\left[\frac{1}{1-\theta_{s}}-\left(\frac{\theta_{s}}{1-\theta_{s}}\right) \Pi_{s, t}^{\epsilon-1}\right]^{\frac{\epsilon}{\epsilon-1}}+\theta_{s} \Pi_{s, t}^{\epsilon} D_{s, t-1}
$$




\subsection{The Government}

The government runs a balanced budget in each period. Hence, lump-sum taxes equal to the total subsidies:

$$
\mathcal{T}_{t} \equiv \tau_{s} P_{s, t} Y_{s, t}+\tau_{f} P_{f, t} Y_{f, t},
$$

where $\tau_{a}, a=\{s, f\}$, is the rate at which the revenues of sector $a$ are taxed.

\subsection{The Exogenous Processes}

The exogenous shock process $Z_{a, t}$ of sector $a$ evolves as

$$
Z_{a, t}=Z_{a, t-1}^{\rho_{z, a}} \exp \left(\epsilon_{a, t}\right),
$$

Hence, the logarithm of $Z_{a, t}$ follows a first-order autoregressive processes with AR(1) persistence parameter $\rho_{z, a}$ and shock $\epsilon_{a, t}$, which is assumed to be independent of the shock in the other sector at all leads and lags, serially uncorrelated and normally distributed with mean zero and variance $\sigma_{a}^{2}$.

\subsection{Competitive Equilibrium}

A stationary competitive equilibrium is defined as a set of stationary processes $W_{t} / P_{t}, N_{t}, C_{t}, R_{t}, Y_{t}, Y_{s, t}, Y_{f, t}, X_{s, t}, X_{f, t}, T_{t}, N_{s, t}, N_{f, t}, H_{s, t}, H_{f, t}, K_{s, t}, K_{f, t}, \Pi_{t}$, $\Pi_{s, t}, \Pi_{f, t}, D_{s, t}, D_{f, t}, Z_{s, t}$ and $Z_{f, t}$, such that the first-order conditions for an optimum hold and the goods and labor markets clear. ${ }^{5}$ Two additional conditions are given by relative price identity, $T_{t}=\frac{\Pi_{s, t}}{\Pi_{f, t}} T_{t-1}$, and the aggregate inflation identity, $\Pi_{t}=\Pi_{s, t}^{\eta} \Pi_{f, t}^{1-\eta}$. The initial values $Z_{s,-1}, Z_{f,-1}, T_{-1}, D_{s,-1}$ and $D_{f,-1}$ are given. We still lack one equation to solve the model, which is the monetary policy rule implemented by the central bank. We will derive it below.

\section{Sticky Price Equilibrium and Loss Function}

We assume that the output subsidy $\tau_{a}$ for sector $a=\{s, f\}$ is set such that it removes the monopolistic competition distortion. Hence, $\tau_{a}=\frac{1}{\epsilon-1}$. We then proceed as follows. First, given that the steady state is efficient, we log-linearize the model around this efficient steady state. Second, following the lead of Woodford (2003) and using the

5 The goods market clearing condition is

$$
Y_{t}=C_{t}+X_{s, t}+X_{f, t}
$$

where $X_{s, t}=\Gamma^{1-\chi}\left(\frac{W_{t}}{P_{t}}\right)^{1-\chi} D_{s, t}$ and $X_{f, t}=\Gamma^{1-\chi}\left(\frac{W_{t}}{P_{t}}\right)^{1-\chi} D_{f, t}$, where $D_{s, t}$ and $D_{f, t}$ are the distortionary losses arising from price stickiness. As shown in the Appendix (Electronic Supplementary Material), we can analogously write the labor market clearing condition. 
log-linearized equations, we derive the micro-founded loss function. Finally, based on the loss function, we obtain the optimal monetary policy rule.

In the sequel, for a generic variable $X$, we define $\tilde{x}=\widehat{x}-x^{*}$, where $\widehat{x}$ is the loglinearized value of $x$ under the sticky-price equilibrium and $x^{*}$ is the log-linearized value of $x$ under the flexible-price equilibrium. Flexible prices refer to the situation in which all intermediate good producers can change the price of their product each period. ${ }^{6}$

\subsection{The Sticky-Price Equilibrium}

Here, we provide a log-linearization of the structural equations. Under a first-order approximation, our price dispersion measure does not play any role, as it is of second order. The dynamics under sticky prices, derived in Appendix C (Electronic Supplementary Material), are given by

$$
\begin{gathered}
\tilde{y}_{t}=\mathbb{E}_{t} \tilde{y}_{t+1}-\Xi\left[r_{t}-\mathbb{E}_{t}\left(\eta \pi_{s, t+1}+(1-\eta) \pi_{f, t+1}\right)-r_{t}^{n *}\right], \\
\pi_{s, t}=\kappa_{s}\left[\Theta \widetilde{y}_{t}-(1-\eta) \widetilde{T}_{t}\right]+\beta \mathbb{E}_{t} \pi_{s, t+1}, \\
\pi_{f, t}=\kappa_{f}\left[\Theta \widetilde{y}_{t}+\eta \widetilde{T}_{t}\right]+\beta \mathbb{E}_{t} \pi \tau_{f, t+1}, \\
\Delta \widetilde{T}_{t}=\pi_{s, t}-\pi_{f, t}-\Delta T_{t}^{*},
\end{gathered}
$$

where $\Xi \equiv \sigma^{-1}(1+\chi(\phi+\sigma)), \Theta \equiv \frac{(1-\chi)(\phi+\sigma)}{1+\chi(\phi+\sigma)}$ and $\Delta$ is the first difference operator. Here, $r_{t}^{n *}$ and $T_{t}^{*}$ are the interest rate, respectively the log-linearised value of the relative price under the flexible-price equilibrium in period $t$. We have that $\Delta T_{t}^{*} \equiv \Delta z_{f, t}-\Delta z_{s, t}$. Hence, we have four equations and five endogenous variables, i.e. $\tilde{y}_{t}, \pi_{s, t}, \pi_{f, t}, \widetilde{T}_{t}$ and $r_{t}$. We still need a monetary policy equation to close the model and solve for the complete set of endogenous variables.

We avoid choosing an arbitrary monetary policy equation, but rather derive an optimal rule based on the micro-foundations provided by our model. We assume that the monetary authority aims at maximizing the utility of the representative household. Hence, we derive the relevant loss function by taking a second-order approximation to its utility function. Note that, with the appropriate subsidy in place, the flexibleprice equilibrium corresponds to the efficient equilibrium and we only need a firstorder approximation of the structural equations in order to derive the second-order approximation of the utility function. ${ }^{7}$ The loss function is

$$
L=\mathbb{E}_{0} \sum_{t=0}^{\infty} \beta^{t}\left(\lambda_{y} \tilde{y}_{t}^{2}+\lambda_{\pi, s} \pi_{s, t}^{2}+\lambda_{\pi, f} \pi_{f, t}^{2}\right),
$$

\footnotetext{
6 Note that we can define the output gap here as the difference between the logarithm of output under the sticky-price and the flexible-price equilibrium. This is so, because with the appropriate subsidy in place, allocations under flexible prices correspond to those under the efficient equilibrium.

7 In order to ensure that the real wage is the same across individuals, even though they work in different sectors, we can either assume perfect income risk sharing among the individuals or the existence of a perfectly competitive labour market.
} 
where $\kappa_{1} \equiv \frac{1}{1+\chi(\phi+\sigma)}, \kappa_{s} \equiv \frac{\left(1-\theta_{s} \beta\right)\left(1-\theta_{s}\right)}{\theta_{s}}, \kappa_{f} \equiv \frac{\left(1-\theta_{f} \beta\right)\left(1-\theta_{f}\right)}{\theta_{f}}, \lambda_{y} \equiv\left(\frac{\sigma+\phi}{2}\right) \kappa_{1}^{2}$, $\lambda_{\pi, s} \equiv \frac{\eta \epsilon}{2 \kappa_{s}}$ and $\lambda_{\pi, f} \equiv \frac{(1-\eta) \epsilon}{2 \kappa_{f}}$. It is easy to see that $\kappa_{a}$ for sector $a$ is decreasing in $\theta_{a}$, hence $\lambda_{\pi, a}$ is increasing in $\theta_{a}$. Further, if $\theta_{a}$ converges zero, then $\kappa_{a}$ goes to infinity and $\lambda_{\pi, a}$ goes to zero. Quite naturally, since consumption fluctuations harm utility, the monetary authority aims at reducing output gap fluctuations. However, it also tries to reduce fluctuations in sectoral inflation rates. The reason is that, because of the inability to reset prices each period, fluctuations in sectoral inflation rates lead to differences in the amounts of the various intermediates deployed in the production of final output and, therefore, to losses of final output (recall that final output is maximized when all intermediate inputs are deployed in equal quantities). In maximizing the representative individual's utility, the monetary authority trades off the output gap against the sector level inflation rates given the optimal weights just stated. In the extreme case in which the prices in sector $f$ are fully flexible, the price index of this sector does not enter the loss function. Hence, fluctuations in these prices leave the representative individual's welfare unaffected. This result is in line with Aoki's (2001) finding that in an economy with a sticky and a fully flexible price sector, the monetary authority should ignore the price fluctuations in the latter sector. Hence, we find here that this result also holds in the presence of factor demand linkages.

The key objective of this paper is to determine the role of factor demand linkages for the economy. The weight associated with inflation in sector $a, \lambda_{\pi, a}$, does not depend on the factor demand linkage parameter $\chi$, while the weight associated with the output gap, $\lambda_{y}$, is decreasing in $\chi$. Hence, the weights of the sectoral inflation rates relative to output, $\frac{\lambda_{\pi, s}}{\lambda_{y}}$ and $\frac{\lambda_{\pi, f}}{\lambda_{y}}$, are increasing in $\chi$. We summarize this finding in:

Proposition 1 The weights associated with the sector level inflation rates relative to output in the individual's loss function are positively related to the strength $\chi$ of the factor demand linkage.

The intuition for this proposition is the following. A stronger factor demand linkage amplifies the response of the economy to technology shocks. Therefore, the misallocation of resources resulting from sectoral inflation rates deviating from their steady states weighs relatively more heavily in the individual's loss function.

\subsection{The Monetary Policy Rule}

The aim of the central bank is to minimize loss function (22), subject to the underlying economic dynamics given by (19), (20) and (21). We assume that the central bank is not constrained in setting the short-term nominal interest rate $r_{t}$ and, hence, there is no need to include the Euler equation (18) as a constraint. ${ }^{8}$ Hence, we can write the Lagrangian as

\footnotetext{
8 Through simulations we verify that the short-term nominal interest rate never touches the zero lower bound and, hence, that the monetary authority is never constrained in setting $r_{t}$. As long as this is the case, the Lagrange multiplier associated with the Euler equation will be zero.
} 


$$
\begin{aligned}
\mathcal{L}= & \mathbb{E}_{0} \sum_{t=0}^{\infty} \beta^{t}\left\{\frac{1}{2}\left(\lambda_{y} \tilde{y}_{t}^{2}+\lambda_{\pi, s} \pi_{s, t}^{2}+\lambda_{\pi, f} \pi_{f, t}^{2}\right)\right. \\
& +\Lambda_{s, t}\left(\pi_{s, t}-\kappa_{s}\left(\Theta \widetilde{y}_{t}-(1-\eta) \widetilde{T}_{t}\right)-\beta \mathbb{E}_{t} \pi_{s, t+1}\right) \\
& +\Lambda_{f, t}\left(\pi_{f, t}-\kappa_{f}\left(\Theta \widetilde{y}_{t}+\eta \widetilde{T}_{t}\right)-\beta \mathbb{E}_{t} \pi_{f, t+1}\right) \\
& \left.+\Lambda_{T, t}\left(\widetilde{T}_{t}-\widetilde{T}_{t-1}-\pi_{s, t}+\pi_{f, t}+T_{t}^{*}-T_{t-1}^{*}\right)\right\}
\end{aligned}
$$

where $\Lambda_{s, t}, \Lambda_{f, t}$ and $\Lambda_{T, t}$ are the period- $t$ Lagrange multipliers associated with (19), (20), respectively (21). The first-order conditions with respect to $\pi_{s, t}, \pi_{f, t}, \widetilde{y}_{t}$ and $\widetilde{T}_{t}$ are, respectively,

$$
\begin{gathered}
\frac{\partial \mathcal{L}}{\partial \pi_{s, t}}=0 \Rightarrow \lambda_{\pi, s} \pi_{s, t}+\Lambda_{s, t}-\Lambda_{s, t-1}-\Lambda_{T, t}=0, \\
\frac{\partial \mathcal{L}}{\partial \pi_{f, t}}=0 \Rightarrow \lambda_{\pi, f} \pi_{f, t}+\Lambda_{f, t}-\Lambda_{f, t-1}+\Lambda_{T, t}=0, \\
\frac{\partial \mathcal{L}}{\partial \widetilde{y}_{t}}=0 \Rightarrow \lambda_{y} \widetilde{y}_{t}-\kappa_{s} \Theta \Lambda_{s, t}-\kappa_{f} \Theta \Lambda_{f, t}=0, \\
\frac{\partial \mathcal{L}}{\partial \widetilde{T}_{t}}=0 \Rightarrow \kappa_{s}(1-\eta) \Lambda_{s, t}-\kappa_{f} \eta \Lambda_{f, t}+\Lambda_{T, t}-\beta \mathbb{E}_{t} \Lambda_{T, t+1}=0 .
\end{gathered}
$$

In the appendix (Electronic Supplementary Material) we show that these first-order conditions together with (19), (20) and (21) satisfy the Blanchard-Kahn conditions. Hence the solution of this system of difference equations is unique and bounded. ${ }^{9}$ As the technology shock processes are assumed to be stationary, the long-run values of the endogenous variables will correspond to their steady-state values. It can be observed that the steady-state values of the Lagrange multipliers associated with (19), (20) and (21) are zero. Hence, optimal monetary policy in the long run does not depend on the choice of the aggregate price index, because the sectoral inflation rates are both at their steady state values. However, in the short run, the monetary authority responds in an optimal way to the technology shocks. To see how, sum the first two first-order conditions to yield, ${ }^{10}$

$$
\lambda_{\pi, s} p_{s, t}+\lambda_{\pi, f} p_{f, t}+\Lambda_{s, t}+\Lambda_{f, t}=\lambda_{\pi, s} p_{s, t-1}+\lambda_{\pi, f} p_{f, t-1}+\Lambda_{s, t-1}+\Lambda_{f, t-1} .
$$

From (23) we observe that the combination $\lambda_{\pi, s} p_{s, t}+\lambda_{\pi, f} p_{f, t}+\Lambda_{s, t}+\Lambda_{f, t}$ is constant over time. Hence, in response to a technology shock the monetary authority optimally targets in the short run the price index $\widetilde{p}_{t} \equiv \lambda_{\pi, s} p_{s, t}+\lambda_{\pi, f} p_{f, t}$ and not the index $p_{t}=\eta p_{s, t}+(1-\eta) p_{f, t}$. This leads us to Proposition 2:

Proposition 2 The optimal price index for the monetary authority to target is $\tilde{p}_{t}=$ $\lambda_{\pi, s} p_{s, t}+\lambda_{\pi, f} p_{f, t}$.

\footnotetext{
${ }^{9}$ We prove this claim in Appendix F (Electronic Supplementary Material).

${ }^{10}$ We use that $\pi_{a, t}=p_{a, t}-p_{a, t-1}$, where $p_{a, t}=\log P_{a, t}$.
} 
The weights associated with the optimal price index are independent of the factor demand linkages, but depend on the weight of each sector in the entire economy in combination with the degree of price stickiness in that sector. More price stickiness in a sector implies a higher weight of that sector in the optimal price index, while under full flexibility the sectoral price index drops out of the optimal price index, in line with Aoki (2001).

By eliminating the Lagrange multipliers, we can obtain the optimal monetary policy rule. It amounts to the following optimal interest rate rule (OIR):

$$
\begin{aligned}
\Delta r_{t}= & \mathcal{A}_{\pi_{s}} \pi_{s, t}+\mathcal{A}_{\pi_{f}} \pi_{f, t}+\mathcal{A}_{\Delta \pi_{s}} \Delta \pi_{s, t}+\mathcal{A}_{\Delta \pi_{f}} \Delta \pi_{f, t}+\mathcal{A}_{\Delta \tilde{y}_{0}} \Delta \tilde{y}_{t} \\
& +\mathcal{A}_{\Delta \tilde{y}_{1}} \Delta \tilde{y}_{t-1}+\mathcal{A}_{\Delta T} \Delta \widetilde{T}_{t}+\Delta r_{t}^{n *}
\end{aligned}
$$

where

$$
\begin{aligned}
\mathcal{A}_{\pi_{s}} \equiv & \frac{\epsilon \sigma(1-\chi) \eta \kappa_{f}}{\beta}, \quad \mathcal{A}_{\pi_{f}} \equiv \frac{\epsilon \sigma(1-\chi)(1-\eta) \kappa_{s}}{\beta}, \quad \mathcal{A}_{\Delta \pi_{s}} \\
\equiv & \frac{\eta}{\beta}, \quad \mathcal{A}_{\Delta \pi_{f}} \equiv \frac{1-\eta}{\beta}, \\
\mathcal{A}_{\Delta \tilde{y}_{0}} \equiv & \frac{\Theta}{\lambda_{y} \beta \Xi}\left[\frac{\lambda_{y}}{\Theta}+\frac{\Theta \eta \epsilon \kappa_{s}}{2}+\frac{\Theta(1-\eta) \epsilon \kappa_{f}}{2}-\left(\eta \kappa_{s}+(1-\eta) \kappa_{f}\right) \Xi \lambda_{y}\right] \\
& +\frac{1}{\beta \Xi}\left(\eta \kappa_{f}+(1-\eta) \kappa_{s}\right), \\
\mathcal{A}_{\Delta \tilde{y}_{1}} \equiv & -\frac{1}{\beta \Xi}, \quad \mathcal{A}_{\Delta T} \equiv-\frac{\left(\kappa_{s}-\kappa_{f}\right) \eta(1-\eta)}{\beta}[\epsilon \sigma(1-\chi)-1] .
\end{aligned}
$$

A number of observations associated with (24) are warranted. First, the OIR describes a unit-root process, hence the short-term interest rate is a difference stationary process. Second, the OIR does not prescribe a purely contemporaneous relation between the short term nominal interest rate, inflation and the output gap. It contains lags of the output gap, the sectoral inflation rates, the relative price index and the natural rate of interest. The presence of these lagged variables confirms the finding of Woodford (2010) that optimal monetary policy will be history dependent and any rule that takes into account only the current and future paths of inflation, the output gap and the relative price index will be unable to implement the optimal allocation. In other words, the OIR requires commitment, because under discretion the monetary authority would focus only on the current and future paths of the endogenous variables. Third, the OIR shown here is not unique. There exist other rules that are consistent with the same optimal equilibrium pattern of responses to the exogenous disturbances. For example, one can substitute (19) into (24), and the resulting rule will yield the same equilibrium outcomes as (24). However, the new rule will not be a direct rule [see Giannoni and Woodford (2003)], as it involves feedback from past, present and expected future real disturbances. Fourth, the OIR is robust in the sense that its derivation does not exploit any of the statistical properties of the technology shocks. Fifth, the formulation of the OIR is symmetric in the sector $s$ and $f$ variables. Sixth, note that $\Delta \widetilde{T}_{t}$ is given as $\pi_{s, t}-\pi_{f, t}-\Delta T^{*}$. Hence, (24) could be simplified by expressing it in terms of the 
responses to $\pi_{s, t}, \pi_{f, t}$ and $\Delta T^{*}$ (and the other variables). However, a nice feature of the current formulation is that the optimal monetary policy rule responds to both the individual sectoral inflation developments and relative price movements between the sectors, in line with the fact that production losses arise from the dispersion of prices within each sector and differences in sectoral price levels. In this connection, it may be observed that the coefficient on flexible (sticky) sector inflation does not depend on the degree of price stickiness of the flexible (sticky) sector. However, what matters are the relative weights attached on the two sectoral inflation rates. Indeed, in the special case in which the prices in the flexible sector become fully flexible, the coefficient on sticky sector inflation becomes infinite, implying that stabilizing flexible-sector inflation loses all relevance relative to stabilizing sticky-sector inflation. Finally, the rule is optimal from a timeless perspective [see Woodford (2003)].

Given that the values of $\chi$ and $\eta$ lie in the interval $(0,1)$, the coefficients of $\pi_{s, t}, \pi_{f, t}, \Delta \pi_{s, t}$ and $\Delta \pi_{f, t}$ in (24) are positive. The monetary authority not only responds to higher inflation in each of the sectors by raising the nominal interest rate, but it also tightens monetary policy in response to a positive change in inflation in each of the sectors. Also, the difference between the coefficients of $\pi_{s, t}$ and $\pi_{f, t}$ is positive, and, hence, the response to inflation in the more sticky sector is larger if $\frac{\kappa_{f}}{\kappa_{s}}>\frac{1-\eta}{\eta}$, which will always hold under our calibration below. Moreover, an increase in the price stickiness of sector $s$ or a reduction in the price stickiness in sector $f$ raises the difference between the coefficients of $\pi_{s, t}$ and $\pi_{f, t}$ and, hence, induces the monetary authority to raise the weight to inflation in the stickier sector compared to that in the more flexible sector.

\subsection{Numerical Investigation of the OIR}

To further enhance our intuition about the responses of the monetary authority to inflation, the output gap and relative price developments, we numerically investigate the weights attached to these variables in (24). However, we need to calibrate the model first. We focus on the U.S. economy and calibrate our two sectors to the goods and services producing sectors. The services producing sector is the more sticky one and, hence, it will serve as the sector $s$ in our model, while the goods producing sector serves as the sector $f$. We follow standard practice and calibrate the model at the quarterly frequency. Most of the parameters we can fix at standard values used in the literature. We set the discount factor $\beta$ at 0.99 , implying a steady-state quarterly nominal interest rate of roughly $1 \%$. Because steady-state inflation is zero, also the quarterly real interest rate is approximately $1 \%$. Using the evidence from Smets and Wouters (2007), the inter-temporal elasticity of substitution is set at 0.5 , implying that $\sigma=2$. The elasticity of substitution between differentiated goods is set at 11 . The Frisch inverse elasticity of the labor supply is fixed at $2,{ }^{11}$ while the AR(1) parameters of the technology shocks are fixed at 0.95 and the variances of the sectoral shocks at 0.009 . The price stickiness

\footnotetext{
11 There is a debate about the value of the Frisch inverse elasticity of the labor supply. Micro estimates suggest a value below 1, while most of the macro calibrations assume a value above 2. Peterman (2016) points out that the micro and macro estimates differ, because of the use of different definitions of Frisch inverse elasticity of the labor supply.
} 
parameters are based on Bils and Klenow (2004) and Nakamura and Steinsson (2008). The median price duration of the services producing sector is 13 months, whereas that of the goods producing sector is 3.3 months. This implies that $\theta_{s}=0.77$ and $\theta_{f}=$ $0.09 .^{12}$ As the expenditure share of services Horvath (2000) uses 0.62. However, as our model features only the goods producing (or manufacturing) and services sectors, which together comprise $92 \%$ of U.S. GDP, we set the weight of sector $s$ at $\eta=\frac{0.62}{0.92}=$ 0.67 . Hence, the weight of sector $f$ is 0.33 . To calibrate the factor demand linkages, we follow Petrella and Santoro (2011) and use the Bureau of Economic Analysis inputoutput table "The Use of Commodities by Industries" for the year 1992. ${ }^{13}$ According to the table, the factor demand linkage from services to manufacturing equals 0.41 , whereas that from manufacturing to services equals 0.14 . These figures are the values of the direct linkages between the sectors, while in intermediates production parameter $\chi$ represents the share of final output, which is in turn composed of inputs from both intermediate sectors. To translate the empirical values of the direct linkages into a calibrated value for $\chi$, substitute the expression for final output production to replace $X_{a, t}(i)$ in the expressions for the production of intermediates in the sectors $a=\{s, f\}$. Then, the intermediate sectors feature as input shares $\chi \eta$ from sector $s,(1-\eta) \chi$ from sector $f$, and $1-\chi$ from labour. Using $\eta=0.67,(1-\eta) \chi=0.14$ implies $\chi=0.42$ for the spill-over from sector $f$ to sector $s$, while $\eta \chi=0.42$ implies $\chi=0.63$ for the spill-over from sector $s$ to sector $f$. Taking a weighted average based on the relative weights of the sectors demanding input from the other sector, we obtain the value $\chi=0.67 * 0.42+0.33 * 0.67=0.50$ that we will use in our numerical analysis. Table 1 summarizes the calibration.

Figure 1 plots the coefficients of $\pi_{s, t}, \pi_{f, t}, \Delta \tilde{y}_{t}, \Delta \tilde{y}_{t-1}$ and $\Delta \widetilde{T}_{t}$ in the optimal interest rate rule as a function of the factor demand linkage parameter (top row), sector $s$ price stickiness (middle row), and the sector $s$ weight (bottom row) while keeping all the other parameters at the values listed in Table 1. The left panels report the coefficients associated with $\pi_{s, t}$ and $\pi_{f, t}$, the middle panels report the coefficients associated with $\tilde{y}_{t}$ and $\tilde{y}_{t-1}$, and the right panels report the coefficients associated with $\Delta \widetilde{T}_{t}$. Recall that the coefficients of $\Delta \pi_{s, t}$ and $\Delta \pi_{f, t}$ are proportional to the weights of the respective sectors and independent of the factor demand linkages and the degrees of price stickiness. Hence, we do not plot them. Notice that the coefficients plotted in Fig. 1 are quite large in magnitude, which is the result of the monetary authority trying to quickly bring down deviations of the output gap and inflation from their steady state values. However, what matters is the relative sizes of these coefficients.

Now, we discuss the intuition behind the behaviour of the coefficients. First, focus on the effect of a change in the strength of the factor demand linkages. The coefficient of inflation in sector $s$ indeed exceeds that of inflation in sector $f$, implying that monetary authority puts more emphasis on inflation in sector $s$. Both coefficients fall

\footnotetext{
12 Boivin et al. (2009) show that prices are more sticky in response to sector-specific shocks than to macroeconomic shocks. In order to overcome the problem of choosing the "right" level of price stickiness, we provide quantitative results for a range of price stickiness levels.

13 As reported by Petrella and Santoro (2011), the input-output table is remarkably stable over time and, hence, focusing on the year 1992 does not affect our analysis. We choose the table for that year to make our results comparable to those of previous studies, in particular Petrella and Santoro (2011). However, below we also study the robustness of our results for different values of the factor demand linkage.
} 
Table 1 Calibration of the parameters

\begin{tabular}{llll}
\hline Parameters & Symbol & Value & Source \\
\hline $\begin{array}{l}\text { Subjective discount factor } \\
\text { Inter-temporal elasticity of }\end{array}$ & $\beta$ & 0.99 & \\
$\quad$ substitution & $1 / \sigma$ & 0.5 & Smets and Wouters (2007) \\
$\begin{array}{l}\text { Intra-temporal elasticity of } \\
\quad \text { substitution }\end{array}$ & $\epsilon$ & 11 & Petrella and Santoro (2011) \\
$\begin{array}{l}\text { Frisch inverse elasticity of } \\
\text { labor supply }\end{array}$ & $\phi$ & & \\
$\begin{array}{l}\text { Factor demand linkage } \\
\text { Weight of sector } s\end{array}$ & $\chi$ & 2 & Peterman (2016) \\
$\begin{array}{l}\text { Price stickiness sector } s \\
\text { Price stickiness sector } f\end{array}$ & $\eta$ & 0.50 & Bureau of Economic Analysis \\
Auto-correlation tech. shock & $\theta_{s}$ & 0.67 & Horvath (2000) \\
$\quad$ sector $s$ & $\rho_{f}$ & 0.77 & Nakamura and Steinsson (2008) \\
Auto-correlation tech. shock & $\rho_{f}$ & 0.09 & Nakamura and Steinsson (2008) \\
$\quad$ sector $f$ & & 0.95 & Petrella and Santoro (2011) \\
Variances shocks sector $s, f$ & $\sigma_{s}^{2}, \sigma_{f}^{2}$ & 0.009 & Smets and Wouters (2007) \\
\hline
\end{tabular}

The table reports the baseline calibration for the deep parameters of the model

when the factor demand linkages become stronger. In fact, they converge to zero when the factor demand linkage parameter $\chi$ converges to one. The same happens with the coefficients on $\Delta \tilde{y}_{t}$ and $\Delta \widetilde{T}_{t}$. The intuition is that, because $\chi$ represents the fraction of final output used as input by the intermediate firms, an increase in $\chi$ lowers the fraction of final output used for consumption. In the limit, when $\chi$ approaches one, there is no consumption and optimal monetary policy does not need to concern itself with stabilizing changes in the output gap nor with changes in inflation, as inflation will no longer cause any welfare losses through losses of final-output production. Similarly, the need to respond to changes in the relative price gap, which also cause output losses, because they cause price dispersion between sectors, weakens. The response to the lagged change in the output gap is typical for these type of models in which it is optimal to commit to an inertial targeting rule. Committing to a prolonged monetary response can dampen movements in inflation expectations - see, for example, Beetsma and Jensen (2005).

We now turn to the effect of sector $s$ price stickiness $\left(\theta_{s}\right)$ on the coefficients in the OIR. An increase in $\theta_{s}$ implies that the monetary authority will put more emphasis on sector $s$ inflation and by extension on aggregate inflation. This will also imply that inflation stabilization will become more important as compared to output stabilization. Hence, the weight on sector $s$ inflation will go up relative to that on sector $f$ inflation and the output gap. The middle panels of Fig. 1 support this intuition. The weights associated with sector $f$ inflation and the output gap fall relative to the weight on sector $s$ inflation. Note that the weight associated with the output gap does not converge to zero. This is because factor demand linkages are still positive and the monetary authority still wants to stabilize output. The middle-right panel shows that the monetary 

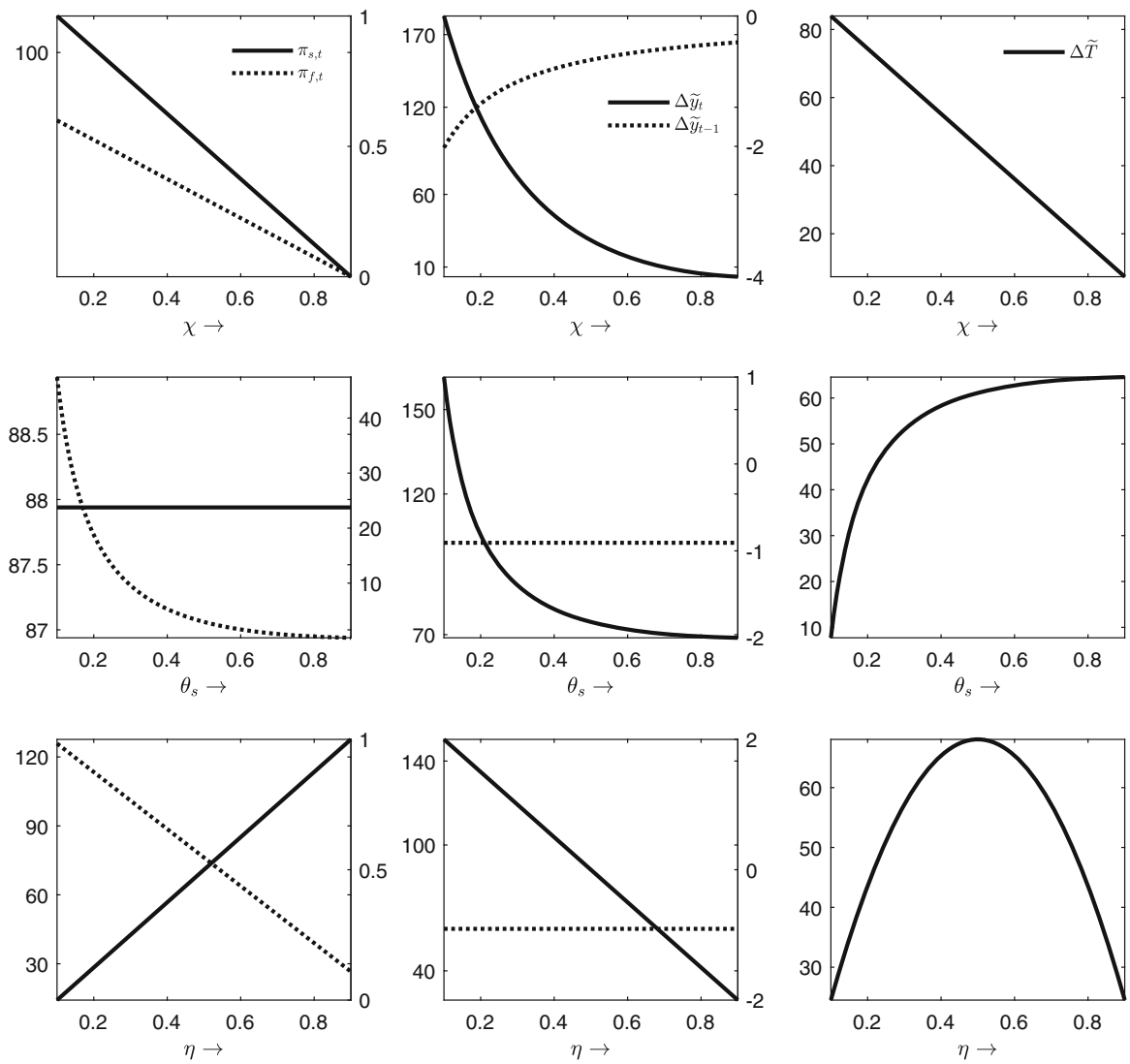

Fig. 1 Coefficients in the OIR (24) as functions of $\chi, \theta_{s}$ and $\eta$. Notes: the figure reports the responses of the coefficients attached to the sectoral inflation rates, the current and lagged output gaps and the change in the relative price in the optimal interest rate rule (24) when the three key parameters $\chi, \theta_{s}$ and $\eta$ are varied in the range $(0.1,0.9)$, while all the other parameters are fixed at their calibrated values reported in Table 1. The top row varies $\chi$, while keeping the other parameters fixed. Similarly, the middle (bottom) row reports the effects of varying $\theta_{S}(\eta)$. The left panels report the coefficients associated with the sectoral inflation rates, the middle panels report the coefficients on the current and lagged output gaps and the right panels report the coefficient on the change in the difference between the sectoral inflation rates relative to the change in the efficient difference between the sectoral inflation rates. For the left panels, the left vertical axis refers to the coefficient on sector $s$ inflation and the right vertical axis to the coefficient on sector $f$ inflation. In the middle panels the left vertical axis refers to $\Delta \tilde{y}_{t}$ and the right vertical axis refers to $\Delta \tilde{y}_{t-1}$

authority puts more weight on the change in the relative price gap as $\theta_{s}$ increases. To see the intuition, recall that $\Delta \widetilde{T}_{t}=\pi_{s, t}-\pi_{f, t}-\Delta T_{t}^{*}$. More price stickiness in the sticky sector also produces larger price dispersion between the sectors, hence leads to larger production losses, ceteris paribus. Hence, it is optimal for the monetary authority to respond more vigorously to a larger deviation of the difference between the actual sectoral inflation rates and the efficient inflation differential.

Finally, the bottom row reports the behavior of the coefficients when the weight of sector $s$, i.e. $\eta$, increases. As the sector $s$ share of the economy increases, stabilizing 
inflation in sector $s$ becomes relatively more important and stabilizing inflation in sector $f$ becomes relatively less important. Also, the relative importance of output stabilization decreases. Hence, the weight on the output gap falls. The coefficient of $\Delta \widetilde{T}_{t}$ (lower-right panel) first increases with $\eta$ and then decreases. As is immediate from its expression, it reaches a maximum at $\eta=0.5$. As discussed, movements in relative prices produce losses arising from misallocation between the sectors. The coefficient on the actual minus efficient inflation differential between the sectors is largest when the sectors are equally large. In this case the loss from price dispersion between the sectors is largest and, hence, the response of the monetary authority to relative price movements is strongest. In other words, an increase in the share $\eta$ of the sticky sector initially induces the monetary authority to work harder to curb the difference in inflation movements between the sectors, while for values of $\eta$ exceeding one-half, a further increase in the relative size of the sticky sector leads the monetary authority to pay less attention to relative inflation developments.

\section{Results}

In this section we first explore the impulse responses of the key endogenous variables with respect to the sectoral productivity shocks. As our objective is to show how the presence of factor demand linkages can affect real allocations in the economy in response to productivity shocks, below we also present a set of impulse responses when the factor demand linkage parameter is set to half its baseline value. Second, using the loss function (22) we analyse how the welfare cost under the OIR varies with the degree of price stickiness in sector $s$ and the strength of the factor demand linkages. Third, we explore the welfare losses associated with misperceptions of these parameters.

\subsection{The Impulse Response Functions}

Figure 2 plots the responses of the endogenous variables when sector $s$ is hit by a positive productivity shock. We do not separately report the responses to the shock in sector $f$, because they are qualitatively the same, though of a different magnitude. The shock raises the real wage, which leads households to raise consumption and lower the labour supply, as the income effect dominates the substitution effect. Higher consumption boosts aggregate demand and, for the market to clear, aggregate output has to increase. Due to the presence of the factor demand linkage, output in both sectors goes up, although the effect is strongest for sector $s$, as this is where the shock originated. Further, the increase in the real wage raises the marginal cost of production in sector $f$, thereby boosting inflation in sector $f$. However, for sector $s$, the effect of the increase in productivity dominates that of the increase in the real wage, thereby leading to negative inflation in sector $s$. As the price stickiness of sector $s$ is $\frac{\theta_{s}}{\theta_{f}}=8.5$ times higher than that of sector $f$, the increase in inflation in sector $f$ is substantially larger than the fall in inflation in sector $s$. However, as $\eta=0.67$, implying that the weight of sector $s$ is twice that of sector $f$, the sectoral inflation 

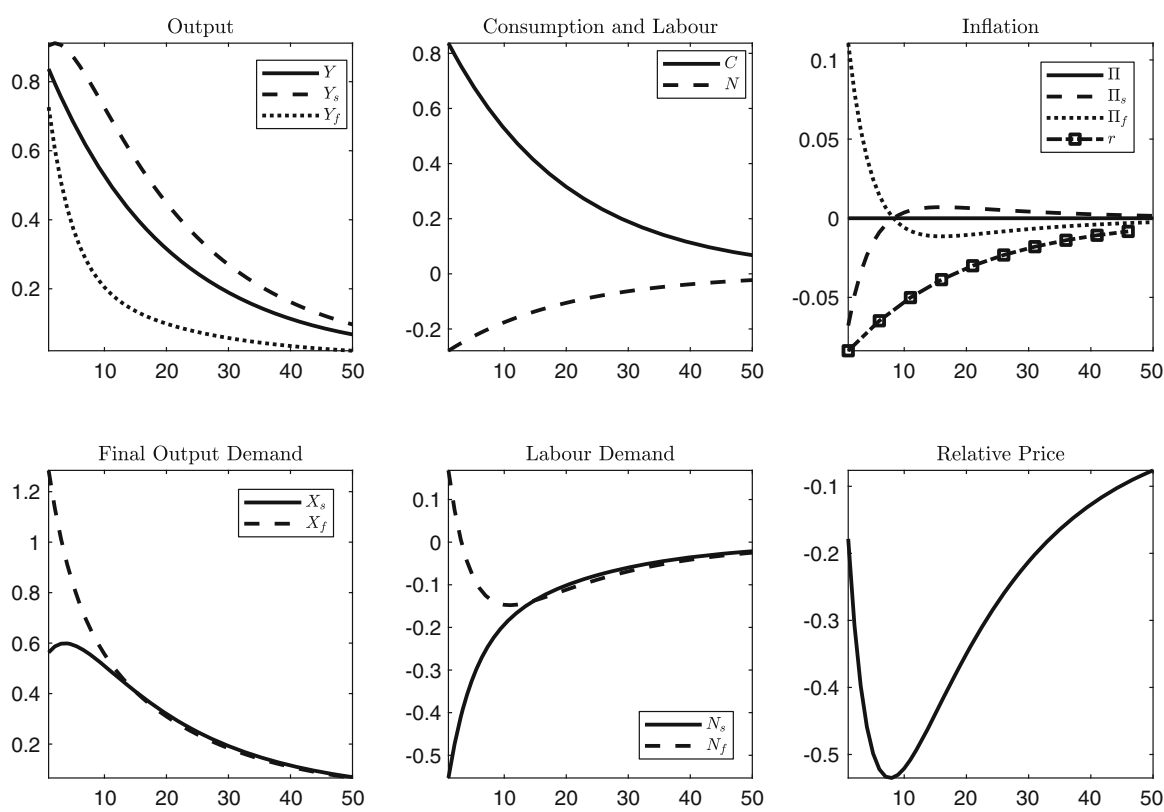

Fig. 2 Impulse response functions following a positive productivity shock in sector $s$-reduced factor demand linkages. Notes: the figure reports the impulse responses of the endogenous variables to a one standard-deviation positive productivity shock in sector $s$. The vertical axis reports the percent deviation of the variable from the steady state

movements roughly cancel each other, implying approximately zero inflation at the aggregate level. As suggested by the predictions of our model, although aggregate inflation barely responds to the productivity shock, the monetary authority reduces the interest rate in response to the decrease in inflation in sector $s$. This shows that monetary authority is putting more emphasis on the behavior of sector $s$ inflation. More importantly, as shown in Fig. 3, when factor demand linkages are weaker, the monetary authority responds less aggressively to sector $s$ inflation.

Due to the factor demand linkages, the increased demand for final output also leads to an increased demand for intermediates. Interestingly, we observe from the lower left panel of Fig. 2 that on impact the demand for final output by the flexible-sector exceeds that by the sticky sector. This is due to the positive productivity shock in sector $s$, which allows the sector $s$ firms to economize on their inputs. However, this effect vanishes as the productivity shock slowly starts to disappear. Initially, the productivity shock also allows sector $s$ producers to economize on labor input, which on impact experiences a fall, while labor input in sector $f$ on impact experiences an increase. The initial decrease in the relative price $T=\frac{P_{s}}{P_{f}}$ of sector $s$ can be explained by the differential behavior of sector level inflation rates described above.

Figure 3 plots the impulse responses when all the parameters are fixed at their baseline values in Fig. 2, except for $\chi$, which is now set to half its original value. A few consequences are noteworthy. First, we find that only the responses of the real variables i.e. sectoral outputs, consumption, labor, final output demand and labor 

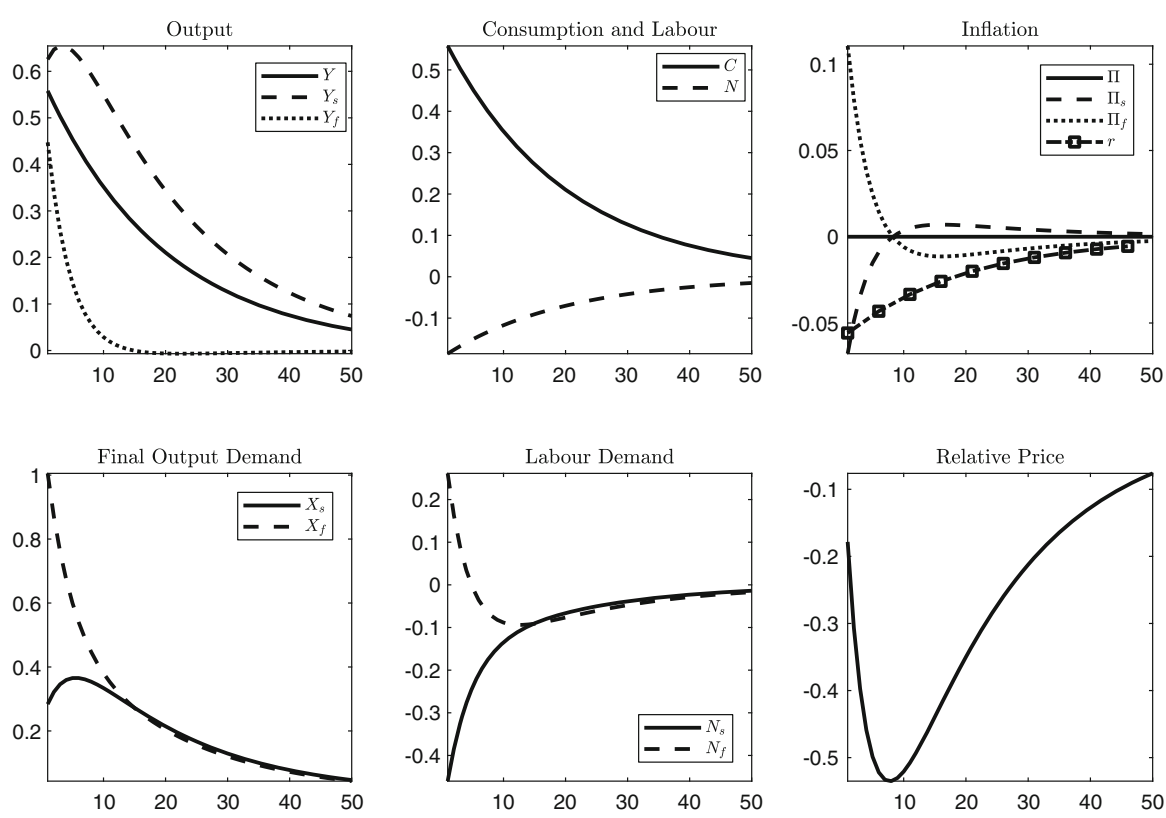

Fig. 3 Impulse response functions following a positive productivity shock in sector $s$. Notes: the figure reports the impulse responses of the endogenous variables to a one standard-deviation positive productivity shock in sector $s$, while $\chi$ is now half its baseline value. The vertical axis reports the percent deviation of the variable from the steady state

demand are affected by the weakening of the factor demand linkages. Second, the responses of the real values to productivity shocks are muted. For example, average sectoral output now increases only by 0.55 percentage points instead of 0.8 percentage points before. Third, the response of sector $f$ output to a sector $s$ productivity shock becomes less persistent.

\subsection{Welfare losses}

The objective of this subsection is to explore how price stickiness in sector $s$ and the magnitude of the factor demand linkages affect the welfare cost associated with sectoral productivity shocks. Following Lucas (1987), we express the welfare cost in terms of the permanent and constant proportional increase in consumption $c^{e q}$, henceforth referred to as the increase in "certainty-equivalent consumption", needed to bring utility in the actual setting to the same level as when consumption is always at its non-stochastic steady-state level $C .{ }^{14}$ In Appendix J (Electronic Supplementary Material) we show that:

\footnotetext{
14 We assume that in their optimization decisions individuals take into account the deterministic character of the setting in this case.
} 

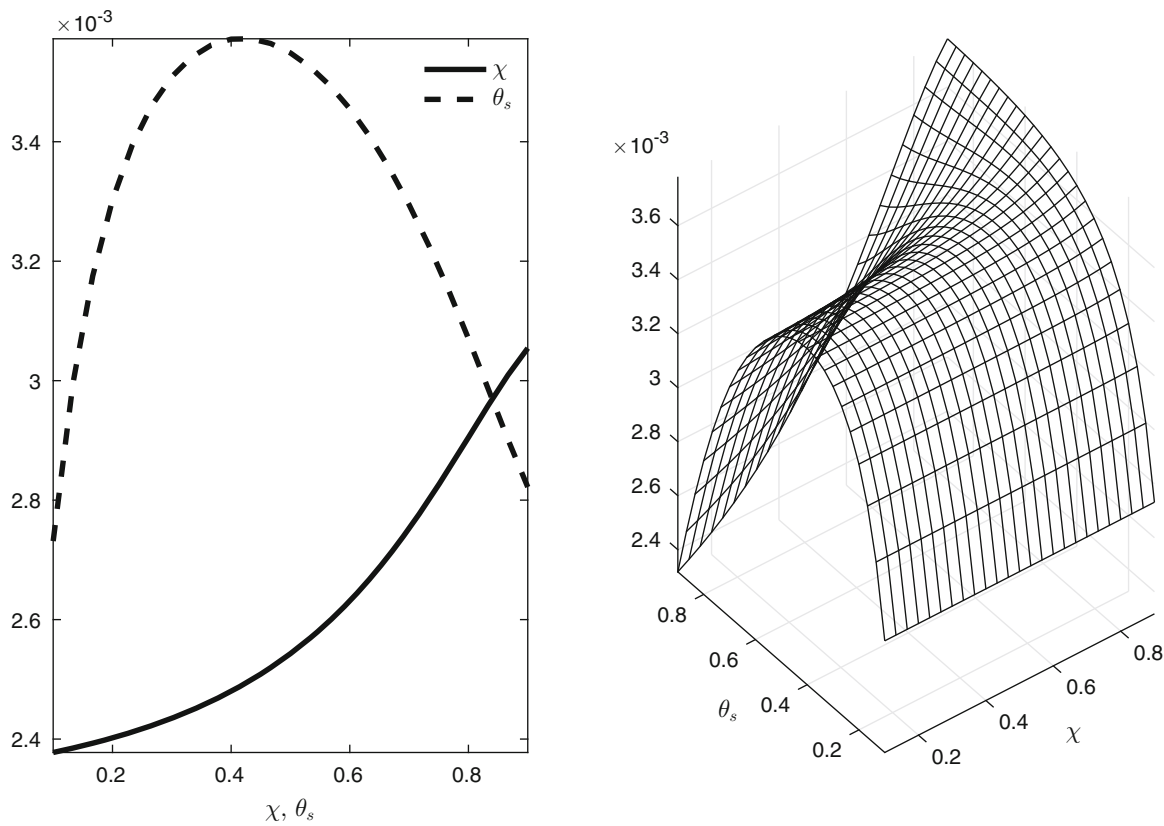

Fig. 4 Welfare costs of sectoral productivity shocks as functions of $\chi$ and $\theta_{s}$. Notes: the left panel shows the welfare loss expressed in terms of a required increase in certainty-equivalent consumption to bring utility at par with utility when consumption is always at its non-stochastic steady-state level when we vary $\chi$ or $\theta_{s}$, while all the other parameters are kept at their baseline values in Table 1 . The right panel allows $\chi$ and $\theta_{s}$ to be simultaneously varied, keeping all the other parameters at their baseline values. The welfare cost computations are based on the simulation of the model over 1000 periods

$$
\frac{c^{e q}}{C}=1-\left[(1-\sigma)\left((1-\beta)(\mathbb{A}-L)+\frac{1}{1+\phi}\right)\right]^{\frac{1}{1-\sigma}}
$$

where $L$ is the loss based on Eq. (22) under the optimal monetary policy rule given the values of the deep parameters and $\mathbb{A}=\frac{\sigma+\phi}{(1-\beta)(1-\sigma)(1+\phi)}$. To compute (25) we first solve the model and then simulate it for 1000 periods. Then, using (22) and the simulated series for the output gap and sectoral inflation, we can compute the loss $L$. The left panel of Fig. 4 reports the welfare costs, when parameter $\chi$ or $\theta_{s}$ are varied, while all the other parameters are kept at their baseline values in Table 1. The right panel varies $\chi$ and $\theta_{s}$ simultaneously, again keeping the other parameters at their baseline values.

Holding all the other parameters at their baseline values, the welfare loss rises with a strengthening of the factor demand linkages — see the left-hand panel of Fig. 4. Intuitively, stronger factor demand linkages have a stronger amplifying effect on the response of the economy to shocks. This amplification effect arises from the spill-over of the original shock to the other intermediate sector via the demand for final output by the originating intermediate sector, a second round effect from the other intermediate sector to the originating intermediate sector, and so on. 

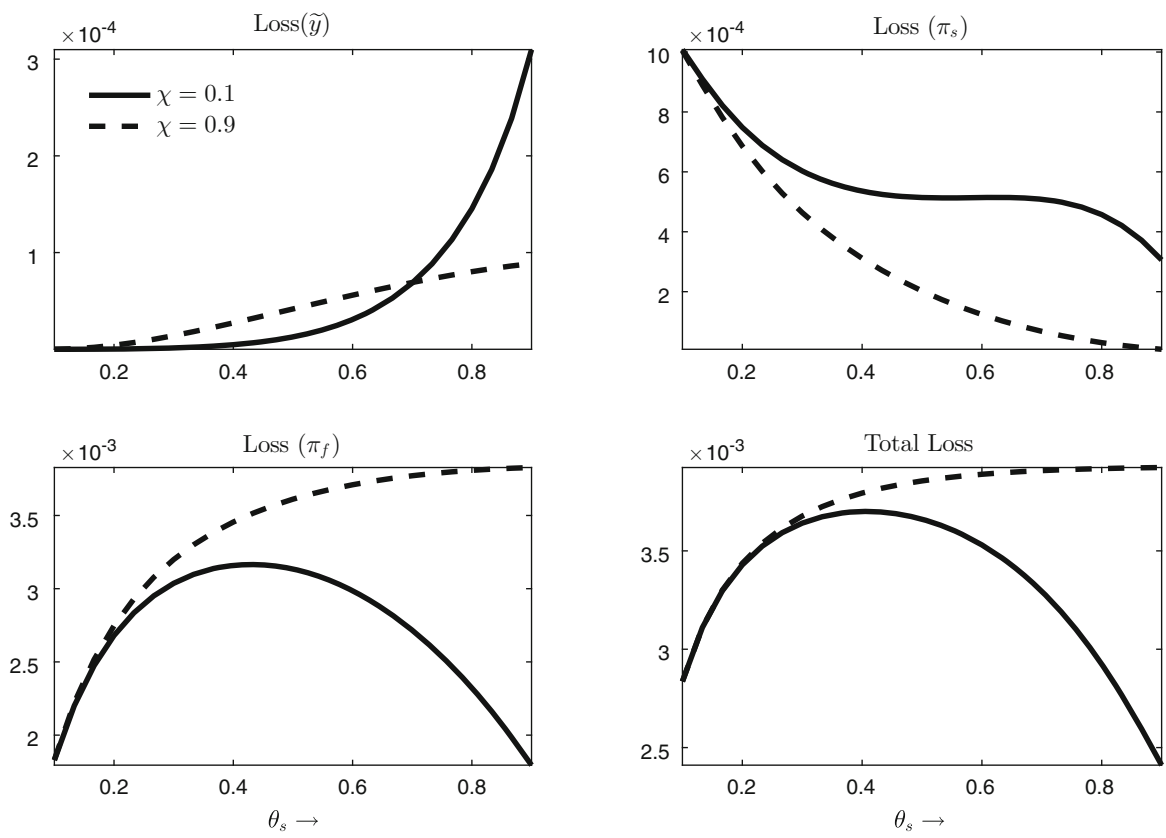

Fig. 5 Welfare loss via (22) and its decomposition for different values of $\chi$ and $\theta_{s}$. Notes: the figure plots the total welfare loss resulting from sectoral productivity shocks as computed via (22), and its decomposition into its three components: the losses due to the fluctuations in the output gap and the two sectoral inflation rates multiplied by their coefficients in (22). The solid lines are based on $\chi=0.1$ and the dashed lines on $\chi=0.9$, while $\theta_{s}$ covers the range $(0.1,0.9)$. The top-left (top-right) panel reports the loss associated with fluctuations in the output gap (sector $s$ inflation). The bottom-left panel reports the loss associated with sector $f$ inflation fluctuations, while the bottom-right panel reports the total loss. The computations are based on the simulation of the model for 1000 periods

The effect of varying $\theta_{s}$ is of particular interest. Figure 4 suggests that the profile of the welfare loss as a function of $\theta_{s}$ depends on the magnitude of the factor demand linkages. When factor demand linkages are relatively weak, the welfare loss reaches a maximum in $\theta_{s}$ on the zero-one interval for $\theta_{s}$, while for relatively strong factor demand linkages, the welfare loss is monotonically increasing in $\theta_{s}$. The non-monotonicity of the welfare loss in sticky-sector price stickiness at low levels of $\chi$ goes against the common wisdom in the literature that higher price stickiness entails higher welfare losses.

There is a one-to-one mapping between the welfare loss as expressed in (25) and the welfare loss computed via (22). For low and high factor demand linkages, in particular $\chi=\{0.1,0.9\}$, and varying sticky-sector price stickiness $\theta_{s}$ over the range $(0.1,0.9)$, Fig. 5 plots the three components of the welfare loss computed via (22), i.e. the average over the simulated series of the discounted sum of the quadratic terms in the output gap and the sectoral inflation rates multiplied by their respective coefficients in (22). Again, the figure is based on solving the model and then simulating it over onethousand periods for each parameter combination that we consider. The total welfare loss itself is depicted in the bottom-right panel of Fig. 5. The figure confirms that the 
total welfare loss reaches a maximum in $\theta_{s}$ for weak factor demand linkages and is monotonically increasing $\theta_{s}$ when factor demand linkages are strong.

To obtain more insight, we consider first the individual loss components. When $\theta_{s}$ is low, output gap stabilization is relatively important. For example, if $\chi=\theta_{s}=$ 0.1 , then $\left(\lambda_{y}, \lambda_{\pi_{s}}, \lambda_{\pi_{f}}\right)=(1.02,0.42,0.25)$. Hence, for low $\theta_{s}$, sectoral inflation fluctuations are relatively large. Because the monetary authority clamps down more and more on sticky-sector inflation when $\theta_{s}$ increases, the loss associated with output gap fluctuations is increasing and that associated with sticky-sector inflation is falling with $\theta_{s}$, despite the increasing weight on sticky-sector inflation fluctuations in the loss function. The fiercer reaction to sticky-sector inflation is in fact partly driven by the amplification effects brought about by the factor demand linkages. As a result we also see that the welfare loss component associated with sticky-sector inflation is in fact lower than that associated with flexible-sector inflation.

To see the overall welfare effect of an increase in price stickiness, notice that, as long as factor demand linkages are weak, price fluctuations in the flexible sector are essentially non-distortive and so relatively greater attention should be geared towards inflation in the sticky sector, which occurs automatically as the degree of price stickiness in this sector rises. For relatively low degrees of price stickiness, the monetary authoritys response to inflation in the sticky sector is relatively weak and so the total welfare loss is increasing in price stickiness, while for relatively high degrees of price stickiness, the reverse applies and the total welfare loss is decreasing in price stickiness. When factor demand linkages are sufficiently strong, however, price fluctuations in the flexible sector are more damaging to welfare as they spill over to the sticky sector. In that case, although the monetary authority responds more aggressively to inflation in the sticky sector as price stickiness rises, this is not enough to offset the indirect welfare losses that arise due to the spillover effects from the flexible sector. ${ }^{15}$

\subsection{Robustness of Optimal Monetary Policy}

In this subsection we explore the additional welfare loss when our OIR is based on a value of the factor demand linkages parameter that differs from its true value or when the monetary authority conducts monetary policy purely on the basis of the relative sizes of the two sectors in the economy, while ignoring the difference in price stickiness between the sectors. Both cases are relevant for policymakers, as it is in practice hard to pinpoint exactly the "true" values of the factor demand linkage or price stickiness. Hence, a rule that produces only limited additional welfare loss when it is conducted under incorrect parameter value assumptions should be relatively attractive for policymakers.

\subsubsection{Uncertainty About the Factor Demand Linkages}

Denote by $c^{0}$ the certainty-equivalent consumption loss in the "optimal" situation when the authority has the correct perception about the factor demand linkages parameter

\footnotetext{
15 Recall from Fig. 1 the generally weaker optimal monetary policy responses to the sectoral inflation rates, the output gap and sectoral price gap differentials when factor demand spill-overs are stronger.
} 


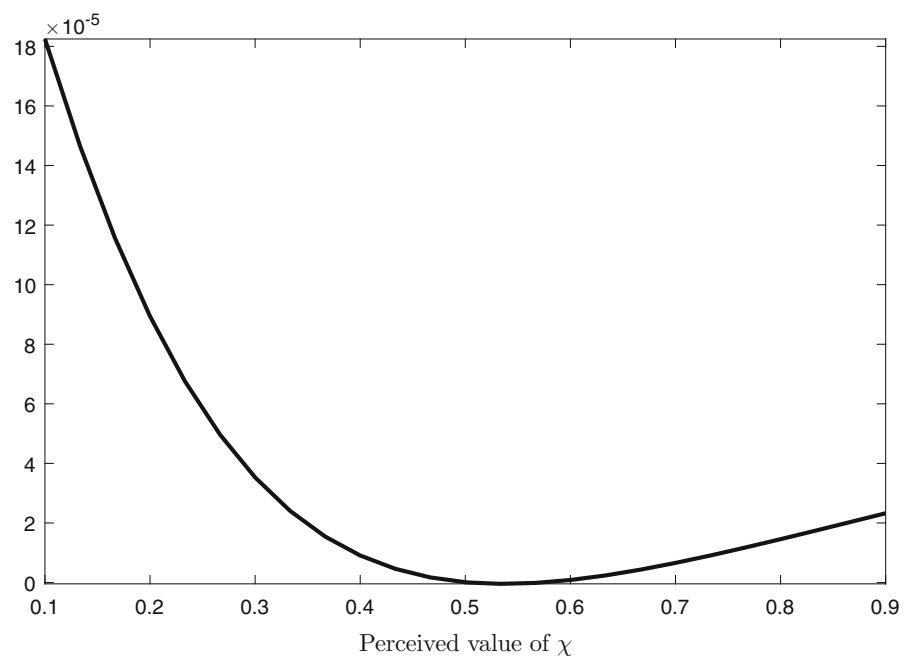

Fig. 6 Additional welfare loss of misperceived strength of factor demand linkages. Notes: this figure plots as a function of the monetary authority's perception of the strength of the factor demand linkages the additional welfare cost as a fraction of non-stochastic steady-state consumption when the authority follows the OIR (24) based on its own perception. The true value of $\chi$ is its baseline value of 0.50 . The additional welfare cost is based on simulating the model over 1000 periods

$\chi$ and by $c^{\text {no }}$ the certainty-equivalent consumption loss in the "non-optimal" case when the monetary authority bases its policy on an incorrect perception of the factor demand linkages parameter. Both cases are based on the OIR for the given (perceived) parameter setting. Using (25), we calculate the additional welfare cost associated with the incorrect perception as $\left(\frac{c^{\mathrm{no}}}{C}-\frac{c^{\mathrm{o}}}{C}\right) \times 100$, where $C$ is again non-stochastic steadystate consumption. Figure 6 plots the additional welfare cost against the perceived value of the factor demand linkages parameter. Obviously, the additional welfare cost is zero when the perceived factor demand linkages parameter equals its true value. The additional welfare loss is increasing in the distance between the perceived and the true factor demand linkages parameter. However, for the current calibration this additional welfare loss is very small and always below one-hundredth of a percent of non-stochastic steady-state consumption.

\subsubsection{Disregarding Differences in Sector Level Price Stickiness}

Figure 7 depicts the additional welfare loss when the monetary authority conducts policy on the basis of the sector weights in the economy, disregarding the difference in price stickiness between the sectors. Concretely, the monetary authority follows the optimal rule based on the loss function (22), but assuming that $\lambda_{\pi_{s}}=\frac{\eta \epsilon}{2 \kappa}$ and $\lambda_{\pi_{f}}=\frac{(1-\eta) \epsilon}{2 \kappa}$ where $\kappa=\frac{(1-\theta \beta)(1-\theta)}{\theta}$ and $\theta=\frac{1}{2}\left(\theta_{f}+\theta_{s}\right)$. The welfare cost is computed in the same manner as in previous section. Denoting by $c^{0}$ the certaintyequivalent consumption loss in the "optimal" case and by $c^{\text {no }}$ the certainty-equivalent consumption loss in the "non-optimal" case when the monetary authority disregards 

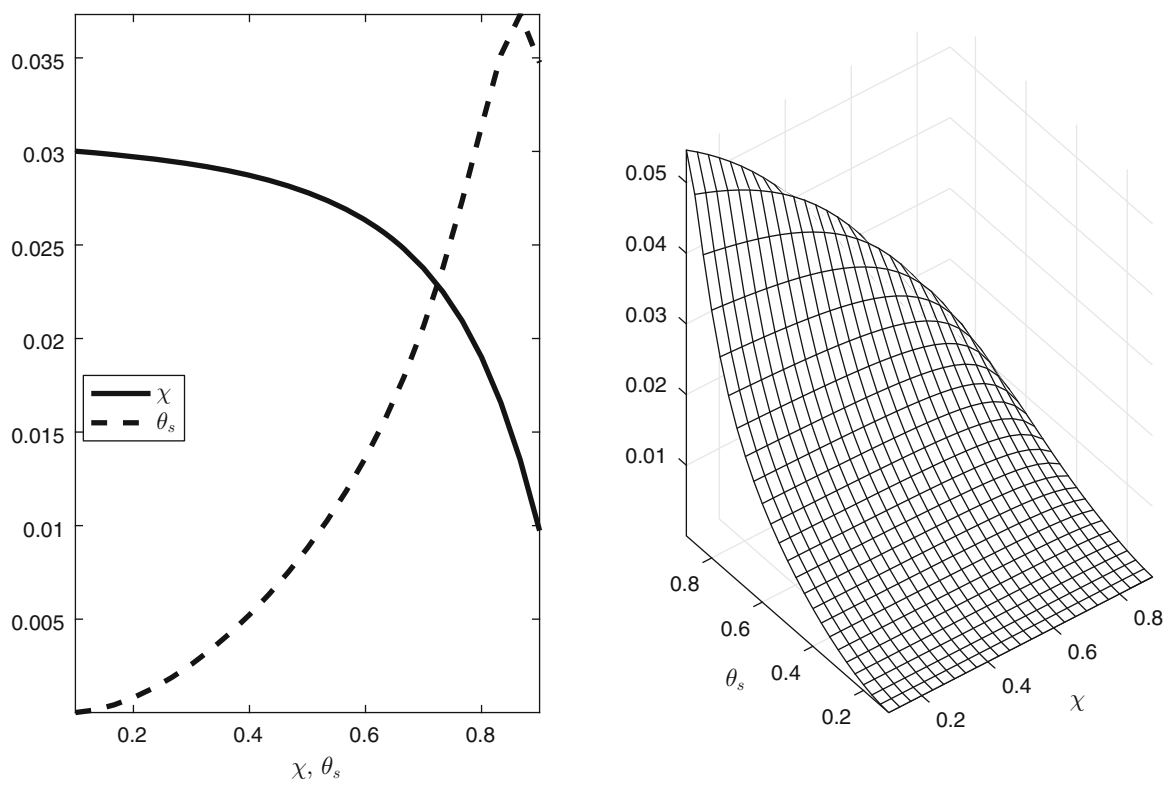

Fig. 7 Additional welfare loss when the inflation weights are based on relative sector sizes ignoring the difference in price stickiness. Notes: the figure plots as a fraction of one the additional welfare loss when the monetary authority bases its policy on a loss function which ignores the difference in price stickiness between the sectors. The benchmark economy is the one in which monetary policy is optimal given the utility-based welfare loss function. The left-hand panel depicts the additional welfare loss when all the parameters other than the one on the horizontal axis are fixed at their baseline values in Table 1, while the right-hand panel makes this assumption for all the parameters other than $\chi$ and $\theta_{s}$, which are varied simultaneously. The welfare loss computation is based on the simulation of the model over 1000 periods

the difference in price stickiness between the sectors, Fig. 7 depicts for different values of $\chi$ and $\theta_{s}$ the additional certainty-equivalent consumption loss relative to non-stochastic steady-state consumption, i.e. $\left(\frac{c^{\text {no }}}{C}-\frac{c^{\mathrm{o}}}{C}\right) \times 100$. The left-hand panel of the figure is based on varying either $\chi$ or $\theta_{s}$, while the right-hand panel is based on varying both parameters simultaneously. The remaining parameters are always kept at their baseline values in Table 1 .

The figure leads to several observations. First, in the left-hand panel the additional welfare cost of attaching the wrong weights to inflation is minimal when $\theta_{s}=\theta_{f}$. The reason is that when price stickiness is identical in both sectors, the weights on the inflation terms in the loss function (22) are indeed proportional to the sector weights. Second, the welfare loss of selecting monetary policy based on the wrong inflation weights in the loss function can be non-negligible for the current calibration and reach a maximum certainty-equivalent consumption loss of a few percent. Third, for given sticky-sector price stickiness, the welfare loss is monotonically decreasing with the strength of the factor demand linkages. There are two reasons for this. Disregarding price stickiness and focusing on relative sector weights only, leads the monetary authority to attach a too low relative weight to sticky-sector inflation in its loss function. An increase in $\chi$ partially corrects this, because it reduces the weight $\lambda_{y}$ on the 
output gap as $\frac{\partial \lambda_{y}}{\partial \chi}<0$, while leaving $\lambda_{\pi_{s}}$ and $\lambda_{\pi_{f}}$ unchanged. While the importance of sticky-sector inflation relative to flexible-sector inflation thus remains unchanged, the importance of sticky-sector inflation relative to the output gap gains in importance, thereby shifting policy somewhat into the direction of the optimal policy setting. The other reason is that, because of the stronger inflation spill-overs between the sectors when the factor demand linkages strengthen, the distinction between clamping down on sticky-sector inflation versus clamping down on flexible-sector inflation becomes less important. Hence, the relative overemphasis on clamping down flexible sector inflation when attaching weights in accordance to the sector sizes becomes less harmful for welfare. Not surprisingly, from the right-hand panel we observe that for low values of $\theta_{s}$, the effect of an increase in the factor demand linkage on the additional welfare loss is very small. The reason is that at low values of $\theta_{s}$ the additional welfare loss associated with the wrong inflation weights is only small.

\section{Conclusion}

This paper has explored the consequences for optimal monetary policy of factor demand linkages between sectors, while allowing for different degrees of price stickiness in the sectors of the economy, thereby calibrating our model to the U.S. situation. We find that factor demand linkages amplify the fluctuations of the economy, because price fluctuations in one sector feed into the other sector. This has consequences for optimal monetary policy, which should become relatively more concerned with stabilizing inflation as opposed to stabilizing the output gap when factor demand linkages become stronger. We derive the micro-founded loss function and the optimal interest rate rule in the presence of a subsidy which eliminates the distortion from monopolistic competition, and we characterize how optimal monetary policy is affected by the deep model parameters. Interestingly, the factor demand linkages do not directly affect the relative weights on the sectoral inflation rates, which are driven by the degrees of price stickiness in the sectors. However, if factor demand linkages rise the loss function weight on the output gap falls relative to the weights on the sectoral inflation rates. The cross-sector amplification effects of inflation become stronger, inducing the monetary authority to more actively clamp down on inflation. We also show that, when the factor demand linkages are weak, and holding stickiness in the other sector constant, the welfare loss of productivity shocks may be non-monotonic in the degree of price stickiness of the sticky sector, with the welfare loss initially rising and then falling in price stickiness. This result arises from the fact that the monetary authority has only one instrument to achieve an optimal trade-off among three variables. The additional welfare losses associated with a misperception of the true strength of the factor demand linkages are small, while ignoring differences in price stickiness when setting monetary policy can lead to substantial additional welfare losses.

Various extensions of the analysis in this paper are possible. For example, the paper focuses on a closed economy and it considers only one type of asymmetry between the sectors, viz. differences in price stickiness. Future work could introduce additional elements of realism by relaxing these assumptions, for example by introducing an open-economy setting in which also foreign inputs are allowed in the production of 
intermediates and by allowing for differences in wage stickiness between the sectors. Also, it would be interesting to see the implications of factor demand linkages in the presence of state-dependent pricing [for example, see Dotsey et al. (1999)].

Open Access This article is distributed under the terms of the Creative Commons Attribution 4.0 International License (http://creativecommons.org/licenses/by/4.0/), which permits unrestricted use, distribution, and reproduction in any medium, provided you give appropriate credit to the original author(s) and the source, provide a link to the Creative Commons license, and indicate if changes were made.

\section{References}

Aoki, K. (2001). Optimal monetary policy responses to relative-price changes. Journal of Monetary Economics, 48, 55-80.

Barsky, R., House, C. L., Boehm, C., \& Kimball, M. S. (2016). Monetary policy and durable goods. Working Paper Federal Reserve Bank of Chicago, WP 2016-18.

Beetsma, R. M., \& Jensen, H. (2005). Monetary and fiscal policy interactions in a micro-founded model of a monetary union. Journal of international Economics, 67, 320-352.

Benigno, P. (2004). Optimal monetary policy in a currency area. Journal of International Economics, 63, 293-320.

Bils, M., \& Klenow, P. J. (2004). Some evidence on the importance of sticky prices. Journal of Political Economy, 112, 947-985.

Boivin, J., Giannoni, M. P., \& Mihov, I. (2009). Sticky prices and monetary policy: Evidence from disaggregated US data. American Economic Review, 99, 350-384.

Bouakez, H., Cardia, E., \& Ruge-Murcia, F. J. (2009). The transmission of monetary policy in a multisector economy. International Economic Review, 50, 1243-1266.

Calvo, G. A. (1983). Staggered prices in a utility-maximizing framework. Journal of Monetary Economics, 12, 383-398.

Chetty, R., \& Szeidl, A. (2007). Consumption commitments and risk preferences. The Quarterly Journal of Economics, 122, 831-877.

Dixit, A. K., \& Stiglitz, J. E. (1977). Monopolistic competition and optimum product diversity. American Economic Review, 67, 297-308.

Dotsey, M., King, R. G., \& Wolman, A. L. (1999). State-dependent pricing and the general equilibrium dynamics of money and output. The Quarterly Journal of Economics, 114, 655-690.

Giannoni, M. P., \& Woodford, M. (2003). Optimal inflation targeting rules. NBER working papers 9939, National Bureau of Economic Research, Inc.

Holly, S., \& Petrella, I. (2012). Factor demand linkages, technology shocks, and the business cycle. Review of Economics and Statistics, 94, 948-963.

Horvath, M. (1998). Cyclicality and sectoral linkages: Aggregate fluctuations from independent sectoral shocks. Review of Economic Dynamics, 1, 781-808.

Horvath, M. (2000). Sectoral shocks and aggregate fluctuations. Journal of Monetary Economics, 45, 69106.

Jones, C. I. (2011). Intermediate goods and weak links in the theory of economic development. American Economic Journal: Macroeconomics, 3, 1-28.

Kim, K., \& Kim, Y. S. (2006). How important is the intermediate input channel in explaining sectoral employment comovement over the business cycle? Review of Economic Dynamics, 9, 659-682.

Lombardo, G. (2006). Inflation targeting rules and welfare in an asymmetric currency area. Journal of International Economics, 68, 424-442.

Lucas, R. E. (1987). Models of business cycles (Vol. 26). Oxford: Basil Blackwell.

Nakamura, E., \& Steinsson, J. (2008). Five facts about prices: A reevaluation of menu cost models. The Quarterly Journal of Economics, 123, 1415-1464.

Peterman, W. B. (2016). Reconciling micro and macro estimates of the Frisch labor supply elasticity. Economic Inquiry, 54, 100-120.

Petrella, I., Rossi, R., \& Santoro, E. (2017). Monetary policy with sectoral trade-offs. The Scandinavian Journal of Economics. https://doi.org/10.1111/sjoe.12266. 
Petrella, I., \& Santoro, E. (2011). Input output interactions and optimal monetary policy. Journal of Economic Dynamics and Control, 35, 1817-1830.

Smets, F., \& Wouters, R. (2007). Shocks and frictions in US business cycles: A Bayesian DSGE approach. American Economic Review, 97, 586-606.

Woodford, M. (2003). Interest and prices: Foundations of a theory of monetary policy. Princeton: Princeton University Press.

Woodford, M. (2010). Optimal monetary stabilization policy. Technical report, National Bureau of Economic Research.

\section{Affiliations}

\section{Swapnil Singh ${ }^{1,2} \cdot$ Roel Beetsma $3,4,5,6,7,8$}

Swapnil Singh

ssingh@lb.lt

1 Center for Excellence in Finance and Economics Research, Bank of Lithuania, Vilnius, Lithuania

2 Kaunas University of Technology, Kaunas, Lithuania

3 MN Chair in Pension Economics, Amsterdam School of Economics, University of Amsterdam, P.O. Box 15867, 1001 NJ Amsterdam, The Netherlands

4 European Fiscal Board, Brussels, Belgium

5 CEPR, London, United Kingdom

6 CESifo, Munich, Germany

7 Netspar, Tilburg, The Netherlands

8 Tinbergen Institute, Amsterdam, The Netherlands 